\title{
Magnetic resonance imaging of brain anomalies in adult and pediatric schizophrenia patients: Experience of a Romanian tertiary hospital
}

\author{
FLORIS PETRU ILIUTA ${ }^{1,2^{*}}$, MIHNEA COSTIN MANEA ${ }^{1,2}$, MAGDALENA BUDISTEANU $^{3-5 *}$, \\ EMANUELA ANDREI $^{3 *}$, FLORENTINA LINCA $^{3}$, FLORINA RAD $^{6,7}$, \\ ROMICA CERGAN $^{8,9}$ and ADELA MAGDALENA CIOBANU ${ }^{1,10}$
}

\author{
${ }^{1}$ Department of Psychiatry, 'Prof. Dr. Alexandru Obregia' Clinical Hospital of Psychiatry, 041914 Bucharest; \\ ${ }^{2}$ Department of Psychiatry and Psychology, Faculty of Dental Medicine, 'Carol Davila' University of Medicine and Pharmacy, \\ 010221 Bucharest; ${ }^{3}$ Psychiatry Research Laboratory, 'Prof. Dr. Alexandru Obregia' Clinical Hospital of Psychiatry, \\ 041914 Bucharest; ${ }^{4}$ Laboratory of Medical Genetics, 'Victor Babes' National Institute of Pathology, 050096 Bucharest; \\ ${ }^{5}$ Department of Medical Genetics, Faculty of Medicine, ‘Titu Maiorescu' University, 031593 Bucharest; \\ ${ }^{6}$ Department of Child and Adolescent Psychiatry, 'Prof. Dr. Alexandru Obregia' Clinical Hospital of Psychiatry, \\ 041914 Bucharest; ${ }^{7}$ Discipline of Child and Adolescent Psychiatry, Department of Neurosciences; \\ ${ }^{8}$ Department of Anatomy, 'Carol Davila' University of Medicine and Pharmacy, 050474 Bucharest; \\ ${ }^{9}$ Department of Radiology and Imaging, Clinical Hospital of Orthopedics, Traumatology and \\ Osteoarticular TB, 030167 Bucharest; ${ }^{10}$ Discipline of Psychiatry, Department of Neurosciences, \\ 'Carol Davila' University of Medicine and Pharmacy, 050474 Bucharest, Romania
}

Received May 28, 2021; Accepted June 29, 2021

DOI: $10.3892 /$ etm.2021.10532

\begin{abstract}
Schizophrenia is a severe mental illness with a significant impact on the life of both the patient and the patient's family. Magnetic resonance imaging has proven a useful tool for studying structural changes of the brain in schizophrenia. However, interpreting the published literature presents several challenges. Despite thorough research in recent years, which has included anatomopathological, imaging, electrophysiological, and genetic studies, the intimate pathophysiological mechanisms of this disease are not yet fully elucidated. The present study included patients with schizophrenia diagnosed in the psychiatric clinics from the 'Prof. Dr. Alexandru Obregia' Clinical Psychiatry Hospital between September 2019 and December 2020 Three Tesla magnetic resonance neuroimaging studies were performed. In a significant number of cases, the neuroimaging studies showed association of cerebral modifications such
\end{abstract}

Correspondence to: Dr Mihnea Costin Manea, Department of Psychiatry, 'Prof. Dr. Alexandru Obregia' Clinical Hospital of Psychiatry, 10 Berceni Street, 041914 Bucharest, Romania

E-mail: maneamihnea@gmail.com

*Contributed equally

Key words: schizophrenia, magnetic resonance imaging, brain, abnormalities, biomarkers as enlargement of the Virchow spaces, lesions of the white matter with demyelinating appearance, and inflammatory sinus reactions. Cortical atrophy and hemosiderotic spots were present in a statistically significant proportion in the patient group with an age range of 29-61 years. MRI is indicated as a useful technique in the follow-up process of schizophrenia patients. However, whether the anomalies revealed in this disorder can be utilised as diagnostic biomarkers is still being debated.

\section{Introduction}

Schizophrenia is one of the most common psychiatric disorders, with an annual incidence rate of approximately $0.05 \%$ (1). Although studied for over a century, the neuropathology of schizophrenia is still unknown (2). Schizophrenia is thought to be caused by a complex interplay of genetic and environmental risk factors that affect early brain growth and biological adaptation to life experiences $(3,4)$. With the development of computed tomography (CT) and magnetic resonance imaging (MRI) technologies, the number of imaging studies performed in patients with schizophrenia has increased. Numerous neuroimaging studies have identified structural and functional abnormalities in patients with schizophrenia, but no diagnostic value can be attributed to any change. Thus, studies on brain volume did not show statistically significant differences in MRI investigations between patients with schizophrenia and normal control subjects. Other cerebral anomalies reported in some studies on the imaging aspects of patients with schizophrenia were enlargement of the lateral 
ventricles or only their temporal horn, enlargement of ventricle three or four, and a reduction in the volume of the temporal or frontal or parietal or occipital brain lobes (5-7). In some studies changes in the volume of the corpus callosum have also been reported (8-10). A total of $92 \%$ of imaging studies in patients with schizophrenia reported doubling of the septum pellucidum $(11,12)$. The presence of enlarged Virchow spaces was reported in a significant proportion in patients with schizophrenia compared to the control group (30.3\%) (13).

Najjar and Pearlman described, in a review of 15 imaging studies that included 792 patients with schizophrenia, the presence of a significant proportion of white matter abnormalities, which would suggest the existence of structural and functional dysconnectivity, even in the early stages of psychoses (14). Changes in the structure of the white matter may influence perception, thought and behavior (15).

Imaging studies did not show significant differences between patients in the first psychotic episode and those with chronic forms of schizophrenia except for an expansion of the volume of the lateral ventricles (16-19).

Schizophrenia in pediatric patients described as early onset schizophrenia (EOS), ages 13-18, and very early onset schizophrenia (VEOS), ages $<13$, is observed less frequently than adult-onset schizophrenia, but is generally more severe, from both a clinical and neurobiological perspective (20). Findings from the structural MRI studies of patients with EOS and VEOS have shown smaller total cerebral volume in VEOS patients compared to controls $(21,22)$, increased lateral ventricular volume (21), reduced thalamic volume $(21,23)$, and enlarged cavum septum pellucidum in VEOS vs. controls (24). Information provided by longitudinal studies has shown that in EOS and VEOS patients decrements in grey matter volume in frontal, temporal and parietal cortices were identified over time (25). It is difficult to determine how medication affects the process of grey matter loss in schizophrenia (26). Medication-naive childhood-onset schizophrenia (COS) subjects are difficult to identify due to the severity of the disorder (27). Grey matter loss and ventricular enlargement have been identified in many adult schizophrenia trials using brain MRI, which are progressive (19,28-31). In the literature, it is speculated that since puberty is a period of massive brain reorganization, the grey matter changes in COS would be more pronounced than in the schizophrenic adult population, which may be the trigger or the effect of the more serious COS phenotype (32). Since there are currently no methods for reliably identifying and studying individuals until the onset of schizophrenia, determining when the structural brain abnormalities occurred is difficult (31). Differences in brain volumes between schizophrenic patients and healthy adults are also evident around the time patients receive treatment $(11,33)$. Additionally, it has been found that in schizophrenic individuals, brain volume alterations tend to be most pronounced in the first years of disease $(31,34,35)$.

In this study, neuroimaging studies in adult and pediatric patients with schizophrenia were assessed. The main MRI abnormalities identified in patients with schizophrenia included in the study were: enlarged Virchow spaces, sinusitis, white matter abnormalities, hemosiderotic spots, but also cortical atrophy, cerebral palsy or venous malformations.

\section{Patients and methods}

Patient data. Adult and pediatric patients diagnosed with schizophrenia admitted to the 'Prof. Dr. Alexandru Obregia' Clinical Psychiatry Hospital between September 2019 and December 2020 were included in the study. For the inclusion in the study of patients with schizophrenia, a study protocol was used, which included anamnesis data, clinical evaluation with general clinical examination, neurological examination and psychiatric examination in which the scales specific to schizophrenia were applied [PANSS (36), Calgary Scale (37), Sheehan Disability Scale (38), Addenbrooke's Cognitive Examination (39)] and psychological examination. The diagnosis of schizophrenia was established according to DSM-IV-TR and ICD 10 criteria $(40,41)$.

The inclusion of patients in the study was achieved after the patients or legal guardian signed the informed consent. The study was run in accordance with the World Medical Association Declaration of Helsinki and was approved by the Institutional Ethical Board of the institution Clinical Hospital of Psychiatry 'Prof. Dr. Alexandru Obregia'.

Methods. Magnetic resonance imaging 3 Tesla was performed according to the standard protocol, including T1, T2, FLAIR, DWI, ADC, and SWI sequences.

Patients with contraindications for performing MRI, such as cardiac pacemaker, implanted cardiac defibrillator, internal pacing wires, clips such as cerebral, carotid or aortic aneurysm, cochlear implants, any implant held in by magnet, Swan-Ganz catheter, with claustrophobia or a possibly pregnancy, were excluded. After exclusion criteria, 45 patients [21 male and 24 female; age range 13-61 years with a mean age of 26.71 years and a standard deviation (SD)=14.39] with schizophrenia were qualified to be introduced in the study at this stage.

Statistical analysis. For statistical analysis, the data obtained were entered into Excel documents, then transferred to the IBM SPSS 22 (SPSS, Inc.) statistical analysis program. Statistical analysis was performed using JASP 0.14.1.0 software. The $\chi^{2}$ test and Bayesian contingency Table test were performed. These statistical tests were applied to verify the existence of relationships between variables, personal characteristics of patients and brain abnormalities encountered in schizophrenia. $\mathrm{P}<0.05$ was considered to indicate statistical significance.

\section{Results}

Patient data. The study included 45 patients (21 male and 24 female), with an age range of 13-61 years (mean age, 26.71 years and SD of 14.39).

MRI anomalies. The MRI studies showed variable anomalies, alone or in different combinations: enlarged Virchow spaces in 44 patients, sinusitis in 27 cases, white matter abnormalities in 16 subjects, hemosiderotic spots in 2 patients, cortical atrophy in 4 cases, lacuna and doubling septum pellucidum in 3 patients, respectively, mega cisterna magna and calcification of the falx cerebri in 2 subjects, respectively, and 1 patient had a venous malformation 
Table I. Contingency table concerning the association between sex and brain abnormalities in the patients with schizophrenia $(\mathrm{N}=45)$.

\begin{tabular}{llll}
\hline & \multicolumn{3}{c}{ Sex } \\
\cline { 2 - 4 } Variables & $\mathrm{M}$ & $\mathrm{F}$ & Total \\
\hline
\end{tabular}

Enlarged Virchow spaces

$\begin{array}{lrrr}\text { Absent } & 1 & 0 & 1 \\ \text { Present } & 20 & 24 & 44 \\ \text { Total } & 21 & 24 & 45\end{array}$

White substance abnormalities

$\begin{array}{lrrr}\text { Absent } & 15 & 14 & 29 \\ \text { Present } & 6 & 10 & 16 \\ \text { Total } & 21 & 24 & 45\end{array}$

Sinusitis

Absent

Present

Total

$\begin{array}{lll}6 & 12 & 18\end{array}$

$15 \quad 12$

$21 \quad 24$

Mega cisterna magna

Absent

Present

Total

$\begin{array}{rr}19 & 24 \\ 2 & 0 \\ 21 & 24\end{array}$

Doubling septum pellucidum

$$
\begin{aligned}
& \text { Absent } \\
& \text { Present }
\end{aligned}
$$

Total

$\begin{array}{rr}19 & 23 \\ 2 & 1 \\ 21 & 24\end{array}$

Cortical atrophy

Absent
Present
Total

$\begin{array}{rr}20 & 21 \\ 1 & 3 \\ 21 & 24\end{array}$

Hemosiderotic spots

$\begin{array}{lrrr}\text { Absent } & 19 & 24 & 43 \\ \text { Present } & 2 & 0 & 2 \\ \text { Total } & 21 & 24 & 45\end{array}$

Lacuna

Absent
Present
Total

$\begin{array}{rr}21 & 21 \\ 0 & 3 \\ 21 & 24\end{array}$

Venous malformation

\begin{tabular}{lrrr} 
Absent & 21 & 23 & 44 \\
Present & 0 & 1 & 1 \\
Total & 21 & 24 & 45 \\
Calcification of the falx cerebri & & & \\
Absent & 19 & 24 & 43 \\
Present & 2 & 0 & 2 \\
Total & 21 & 24 & 45 \\
\hline
\end{tabular}

(Table I). A total of 26 of the patients had both enlarged Virchow spaces and sinusitis, and 8 of the patients had both sinusitis and white substance abnormalities.

Considering sex of patients, 24 women and 20 men had enlarged Virchow spaces, 6 men and 10 women had white
Table II. The $\chi^{2}$ tests concerning the association between sex and brain abnormalities in the patients with schizophrenia $(\mathrm{N}=45)$.

\begin{tabular}{lccc}
\hline Variables & Value & df & P-value \\
\hline Enlarged Virchow spaces & 1.169 & 1 & 0.280 \\
White substance abnormalities & 0.838 & 1 & 0.360 \\
Sinusitis & 2.143 & 1 & 0.143 \\
Mega cisterna magna & 2.392 & 1 & 0.122 \\
Doubling septum pellucidum & 0.517 & 1 & 0.472 \\
Cortical atrophy & 0.828 & 1 & 0.363 \\
Hemosiderotic spots & 1.607 & 1 & 0.205 \\
Calcification of the falx cerebri & 2.392 & 1 & 0.122 \\
Lacuna & 2.813 & 1 & 0.094 \\
Venous malformation & 0.895 & 1 & 0.344 \\
\hline
\end{tabular}

matter abnormalities, but without any statistical significance (P>0.05) (Tables I and II).

Sinusitis was one of the most common abnormalities in our sample, but it did not predominate statistically significantly in either sex, although the abnormality was present in 15 men and 12 women $(\mathrm{P}>0.05)$ (Tables I and II).

Calcification of the falx cerebri, mega cisterna magna and hemosiderotic spots were present in 2 of the men, respectively. However, this aspect is not characteristic of the male group as no significant association was found between these variables ( $\mathrm{P}>0.05)$ (Tables I and II).

Lacuna and venous malformation were present in 3 and 1 of the women, respectively; however, no significant correlation was found between sex and the two anomalies $(\mathrm{P}>0.05)$ (Tables I and II).

Doubling septum pellucidum and cortical atrophy were present in both men and women; however, there were no significant differences between them $(\mathrm{P}>0.05)$ (Tables I and II).

Relationship between age and brain abnormalities. Enlarged Virchow spaces, sinusitis and white substance abnormalities were the most common abnormalities of the brain by age category albeit these abnormalities were not a characteristic of any age category from a statistical point of view $(\mathrm{P}>0.05)$ (Tables III and IV).

Mega cisterna magna (4 participants) and calcification of the falx cerebri, (2 participants) and lacuna were present in the second age category (13-28 years) more frequently than in the first age category (29-61 years) albeit there were no statistically significant differences between the two age categories ( $\mathrm{P}>0.05)$ (Tables III and IV).

Cortical atrophy and hemosiderotic spots were present in the second age category (29-61 years) (8 patients) more frequently than in the first category (13-28 years) (1 patient) and there are statistically significant differences between the two age categories $(\mathrm{P}<0.05)$ (Tables III and IV). The statistical significance of cortical atrophy and hemosiderotic spots by age category is shown in Table $\mathrm{V}\left(\mathrm{BF}_{10}\right.$ independent multinomial cortical atrophy $=4.462, \mathrm{BF}_{10}$ independent multinomial hemosiderotic spots=8.675). In addition, in Figs. 1 and 2, it can 
Table III. Contingency table concerning the association between age and brain abnormalities in the patients with schizophrenia $(\mathrm{N}=45)$.

\begin{tabular}{llll}
\hline & \multicolumn{3}{c}{ Age range } \\
\cline { 2 - 4 } Variables & $\begin{array}{lll}13-28 \\
\text { years }\end{array}$ & $\begin{array}{l}29-61 \\
\text { years }\end{array}$ & Total \\
\hline
\end{tabular}

Enlarged Virchow spaces

Absent

Present

Total

White substance abnormalities

$\begin{array}{lrrr}\text { Absent } & 19 & 10 & 29 \\ \text { Present } & 6 & 10 & 16 \\ \text { Total } & 25 & 20 & 45\end{array}$

Sinusitis

Absent
Present
Total

Mega cisterna magna

Absent

Present

Total

$\begin{array}{rr}25 & 18 \\ 0 & 2 \\ 25 & 20\end{array}$

Doubling septum pellucidum

$$
\begin{aligned}
& \text { Absent } \\
& \text { Present }
\end{aligned}
$$

Total

$\begin{array}{rrr}23 & 19 & 42 \\ 2 & 1 & 3 \\ 25 & 20 & 45 \\ & & \\ 25 & 16 & 41 \\ 0 & 4 & 4 \\ 25 & 20 & 45\end{array}$

Hemosiderotic spots

$\begin{array}{lrrr}\text { Absent } & 24 & 16 & 40 \\ \text { Present } & 1 & 4 & 5 \\ \text { Total } & 25 & 20 & 45\end{array}$

Lacuna

Absent
Present
Total

Venous malformation

$\begin{array}{lrrr}\text { Absent } & 24 & 20 & 44 \\ \text { Present } & 1 & 0 & 1 \\ \text { Total } & 25 & 20 & 45\end{array}$

Calcification of the falx cerebri

\begin{tabular}{lrrr} 
Absent & 25 & 18 & 43 \\
Present & 0 & 2 & 2 \\
Total & 25 & 20 & 45 \\
\hline
\end{tabular}

be seen that the differences between the two age categories in terms of the anomalies discussed are strongly supported by the data collected, $\mathrm{BF}_{10}>\mathrm{BF}_{01}$.
Table IV. The $\chi^{2}$ tests concerning the association between age and brain abnormalities.

\begin{tabular}{lccc}
\hline Variables & Value & df & P-value \\
\hline Enlarged Virchow spaces & 0.978 & 1 & 0.323 \\
White substance abnormalities & 0.841 & 1 & 0.175 \\
Sinusitis & 1.201 & 1 & 0.273 \\
Mega cisterna magna & 2.188 & 1 & 0.139 \\
Doubling septum pellucidum & 0.311 & 1 & 0.577 \\
Cortical atrophy & 4.590 & 1 & 0.032 \\
Hemosiderotic spots & 5.881 & 1 & 0.015 \\
Calcification of the falx cerebri & 2.392 & 1 & 0.122 \\
Lacuna & 0.313 & 1 & 0.564 \\
Venous malformation & 0.978 & 1 & 0.322 \\
\hline
\end{tabular}

Table V. Bayesian contingency table tests and the association between age, cortical atrophy, and hemosiderotic spots.

\begin{tabular}{lc}
\hline Variable & Value \\
\hline $\mathrm{BF}_{10}$ independent multinomial cortical atrophy & 4.462 \\
$\mathrm{~N}$ & 45 \\
$\mathrm{BF}_{10}$ independent multinomial hemosiderotic spots & 8.675 \\
\hline
\end{tabular}

Relationship between sex and brain abnormalities in children. The study included 25 pediatric patients ( 12 boys and 13 girls). The age interval was 13-18 years (mean age of 15.08 years; SD of 1.68). Of the 25 patients, 24 had enlarged Virchow spaces, 14 had sinusitis, 6 had white substance abnormalities, 1 had hemosiderotic spots, 2 had lacuna and doubling septum pellucidum, respectively, and 1 of the participants had venous malformation.

Although, 13 of the girls in the sample and 11 of the boys had enlarged Virchow spaces, this brain abnormality no longer predominated in one of the sexes from a statistical point of view $(\mathrm{P}>0.05)$ (Tables VI and VII).

Sinusitis was one of the most common abnormalities in patients in our sample, but did not predominate statistically significantly in either sex $(\mathrm{P}>0.05)$ (Tables VI and VII).

\section{Discussion}

The results obtained in patients of the present study partially overlap with those reported in the literature, in the sense that the enlargement of the Virchow spaces was observed in a high percentage of cases, as was the case for white matter demyelinating lesions, and cortical atrophy. Akhtar et al (13) conducted a comparative study, with a group of 33 schizophrenic patients and a control group of 33 healthy individuals with a mean age of 30 years, in order to determine whether there is any structural changes in brain matter. Enlarged Virchow spaces were identified in 10 (30\%) of all those with schizophrenia and zero of the control subjects. In addition, in that study there were no significant differences by sex, compared to the control group or between individuals in the same group. The presence 


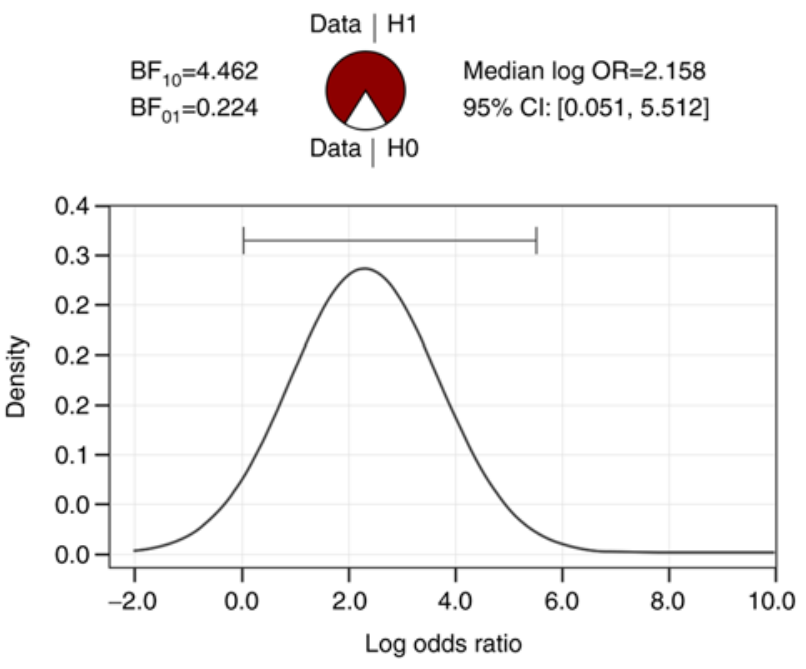

Figure 1. Graphical representation of the relationship between age and cortical atrophy (Bayesian test).
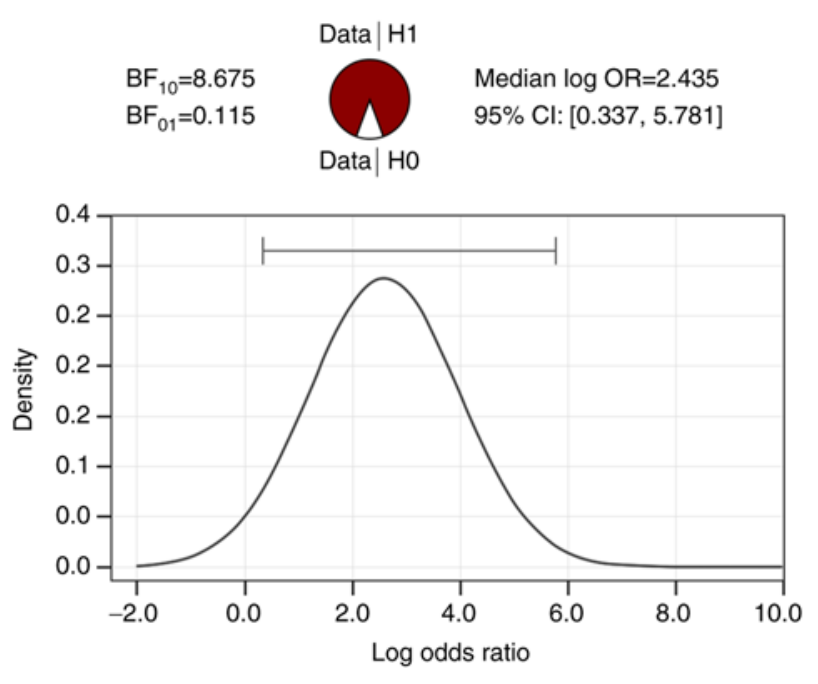

Figure 2. Graphical representation of the relationship between age and hemosiderotic spots (Bayesian test).

of enlarged Virchow spaces in adults was associated with different situations including vascular ectasia, CSF pulsations, abnormal arterial wall permeability, dementia, and hypertension $(42,43)$. Wuerfel et al suggested a role of Virchow spaced in inflammatory processes of the brain (44). The significance of enlarged Virchow spaces in children and adolescents is not clear. A study on children with autism spectrum disorder (ASD) showed an increased incidence of enlarged Virchow spaces in ASD children compared with control group; this anomaly was correlated with the expression of symptoms and with a low adaptative functioning (42).

Sinusitis was also reported in 10 of the cases of schizophrenia and 22 of the individuals in the control group, while in our case sinusitis had a frequency of $60 \%$ of the total number of patients. Davis et al (45) suggested that the MRI shows in patients with schizophrenia a slight, but substantial white matter decrease. Of the 45 patients in the present study, 16 patients had white matter abnormalities, which means a percentage of $35.5 \%$.
Table VI. Contingency table for the association between sex and brain abnormalities in children $(\mathrm{N}=25)$.

\begin{tabular}{|c|c|c|c|}
\hline \multirow[b]{2}{*}{ Variables } & \multicolumn{3}{|c|}{ Sex } \\
\hline & $\mathrm{M}$ & $\mathrm{F}$ & Total \\
\hline \multicolumn{4}{|c|}{ Enlarged Virchow spaces } \\
\hline Absent & 1 & 0 & 1 \\
\hline Present & 11 & 13 & 24 \\
\hline Total & 12 & 13 & 25 \\
\hline \multicolumn{4}{|c|}{ White substance abnormalities } \\
\hline Absent & 9 & 10 & 19 \\
\hline Present & 3 & 3 & 6 \\
\hline Total & 12 & 13 & 25 \\
\hline \multicolumn{4}{|l|}{ Sinusitis } \\
\hline Absent & 5 & 6 & 11 \\
\hline Present & 7 & 7 & 14 \\
\hline Total & 12 & 13 & 25 \\
\hline \multicolumn{4}{|c|}{ Mega cisterna magna } \\
\hline Absent & 12 & 13 & 25 \\
\hline Present & 0 & 0 & 0 \\
\hline Total & 12 & 13 & 25 \\
\hline \multicolumn{4}{|c|}{ Doubling septum pellucidum } \\
\hline Absent & 10 & 13 & 23 \\
\hline Present & 2 & 0 & 2 \\
\hline Total & 12 & 13 & 25 \\
\hline \multicolumn{4}{|c|}{ Cortical atrophy } \\
\hline Absent & 12 & 13 & 25 \\
\hline Present & 0 & 0 & 0 \\
\hline Total & 12 & 13 & 25 \\
\hline \multicolumn{4}{|c|}{ Hemosiderotic spots } \\
\hline Absent & 12 & 12 & 24 \\
\hline Present & 0 & 1 & 1 \\
\hline Total & 12 & 13 & 25 \\
\hline \multicolumn{4}{|c|}{ Calcification of the falx cerebri } \\
\hline Absent & 12 & 13 & 25 \\
\hline Present & 0 & 0 & 0 \\
\hline Total & 12 & 13 & 25 \\
\hline \multicolumn{4}{|c|}{ Venous malformation } \\
\hline Absent & 12 & 12 & 24 \\
\hline Present & 0 & 1 & 1 \\
\hline Total & 12 & 13 & 25 \\
\hline \multicolumn{4}{|l|}{ Lacuna } \\
\hline Absent & 12 & 11 & 23 \\
\hline Present & 0 & 2 & 2 \\
\hline Total & 12 & 13 & 25 \\
\hline
\end{tabular}

In a large number of cases, the presence of a sinus reaction has been identified, both in pediatric and adult patients. Findings have shown there is an association between mental disorders and sinusitis $(46,47)$. The link between schizophrenia and sinusitis could be investigated in order to demonstrate whether patients with schizophrenia 
Table VII. The $\chi^{2}$ test for the association between sex and brain abnormalities in children.

\begin{tabular}{lccc}
\hline Variable & Value & df & P-value \\
\hline Enlarged Virchow spaces & 1.128 & 1 & 0.288 \\
Sinusitis & 0.051 & 1 & 0.821 \\
\hline
\end{tabular}

have a predisposition to developing sinus disorders or whether they develop a chronic inflammatory process. Mega cisterna magna, calcification at falx cerebri level, doubling of the septum pellucidum and gap-type lesions were more frequent in the age category 29-61 years, with no statistically significant differences between the two age categories. Cortical atrophy and hemosiderotic spots were more frequently described in patients aged 29-61 years, with statistically significant differences between the two age categories. Regarding the hemosiderotic spots, lacuna, the venous malformation and the calcification of the falx cerebri found on MRI in the current study, few reports in the literature discuss their manifestation and it is reasonable to conclude that they are not frequent abnormalities of the brain in patients with schizophrenia.

The occurrence of cortical atrophy and the abnormal cavum septum pellucidum are the most common changes on MRI in patients with schizophrenia, according to the literature. Given that 25 of the 45 patients in the current study were children, it is not surprising that only $7(15.5 \%)$ of them documented cortical atrophy or the presence of double septum pellucidum. Childhood-onset schizophrenia (COS) exhibits brain anatomic abnormalities that are close to those observed in adult populations, suggesting that there is a general continuity between these exceptional childhood cases and adult schizophrenia populations.

The research included patients with schizophrenia who were already taking antipsychotic treatment. Concerning utilization of antipsychotic medications by a large number of participants in neuroimaging trials, the effect of antipsychotic medications as a cause of MRI changes was not previously explored (48). Lieberman et al concluded that prescribing haloperidol to patients caused a marked reduction in the grey matter after 12 and 52 weeks, but no reduction was observed in patients who were prescribed olanzapine. Patients were investigated using MRI brain imaging (49). The brain seems to be more damaged after taking typical antipsychotics than atypical ones. This is not the only study reported in medical literature that observed the impact of antipsychotics upon the brain structure. However, data from studies of wider groups of participants shows a progressive association between antipsychotic usage and brain volumetric decrease. Cahn et al reported MRI modifications in 34 schizophrenic patients undergoing treatment with typical and atypical antipsychotics, modification such as increased volume of lateral ventricles and decreased brain volume, especially in grey matter. Patients were prospectively studied for 16 weeks and compared to a control group that did not receive any antipsychotic treatment (50). In a study of
18 antipsychotic-naive schizophrenia patients and 18 stable controls, Jayakumar et al (51) found gray-matter volumetric decreases and higher cerebrospinal fluid volumes, as did Davatzikos et al (52).

Since prior imaging was not available for comparison, the causal relationship between schizophrenia and observed brain changes could not be determined. The relatively small number of investigated cases did not allow the establishment of imaging abnormalities with the role of biomarker, thus an extension of the number of investigated cases being necessary, as well as the comparative evaluation with a similar group of healthy subjects. To create a link between schizophrenia and brain structural abnormalities, larger longitudinal studies with functional imaging are needed.

In summary, MRI can be a helpful method in identifying brain changes in patients with schizophrenia and can also contribute to establishing a long-term prognosis for them. Additionally, MRI may be used to make a differential diagnosis between organic psychoses and those that do not have a neurological substrate $(53,54)$.

\section{Acknowledgements}

Not applicable.

\section{Funding}

The present study was supported partially by a grant from the Romanian National Authority for Scientific Research and Innovation CCCDI-UEFISCDI project number CofundERANET NEURON SYNSCHIZ 6/2018.

\section{Availability of data and materials}

The datasets used and/or analyzed during the current study are available from the corresponding author on reasonable request.

\section{Authors' contributions}

FPI conceived and designed the study, wrote the manuscript, contributed in all stages of the article. MCM analyzed and collecting data regarding MRI findings. MB performed statistical analysis and was involved in revising the manuscript critically for important intellectual content. EA and FL contributed to the data collection and interpretation. FR contributed to reviewing the data and editing of the manuscript. RC confirmed the authenticity of all the imaging investigations and interpreted the results. AMC finalized the analysis and gave the final approval of the version to be published. All authors read and approved the final manuscript.

\section{Ethics approval and consent to participate}

This study was approved by the Ethics Committee of 'Prof. Dr. Alexandru Obregia' Clinical Hospital of Psychiatry, Bucharest, Romania (approval no. 10/21.03.2018). Written informed consent was obtained from each patient/legal guardian of each patient. 


\section{Patient consent for publication}

Not applicable.

\section{Competing interests}

The authors declare that they have no competing interests.

\section{References}

1. Rofman ES: Kaplan and Sadock's synopsis of psychiatry. J Clin Psychiatry 11: 303, 2015.

2. Murray RM, Bhavsar V, Tripoli G and Howes O: 30 years on: How the neurodevelopmental hypothesis of schizophrenia morphed into the developmental risk factor model of psychosis Schizophr Bull 43: 1190-1196, 2017.

3. Howes OD and Murray RM: Schizophrenia: An integrated sociodevelopmental-cognitive model. Lancet 383: 1677-1687, 2014

4. Weinberger DR and Levitt P: Neurodevelopmental origins of schizophrenia. In: Schizophrenia 3rd Edition. Weinberger DR and Harrison PE (eds.) Wiley Blackwell, Oxford, England, pp393-412, 2010.

5. Andreasen NC, Flashman L, Flaum M, Arndt S, Swayze V 2nd, O'Leary DS, Ehrhadt JC and Yuh WT: Regional brain abnormalities in schizophrenia measured with magnetic resonance imaging. JAMA 272: 1763-1769, 1994.

6. Bilder RM, Wu H, Bogerts B, Degreef G, Ashtari M, Alvir JM, Snyder PJ and Lieberman JA: Absence of regional hemispheric volume asymmetries in first-episode schizophrenia. Am J Psychiatry 151: 1437-1447, 1994.

7. Bilder RM, Wu H, Bogerts B, Ashtari M, Robinson D, Woerner M, Lieberman JA and Degreef G: Cerebral volume asymmetries in schizophrenia and mood disorders: A quantitative magnetic resonance imaging study. Int J Psychophysiol 34: 197-205, 1999.

8. Narr KL, Thompson PM, Sharma T, Moussai J, Cannestra AF and Toga AW: Mapping morphology of the corpus callosum in schizophrenia. Cereb Cortex 10: 40-49, 2000.

9. Downhill JE Jr, Buchsbaum MS, Wei T, Spiegel-Cohen J. Hazlett EA, Haznedar MM, Silverman J and Siever LJ: Shape and size of the corpus callosum in schizophrenia and schizotypal personality disorder. Schizophr Res 42: 193-208, 2000.

10. Chua SE, Sharma T, Takei N, Murray RM and Woodruff PW: A magnetic resonance imaging study of corpus callosum size in familial schizophrenic subjects, their relatives, and normal controls. Schizophr Res 41: 397-403, 2000.

11. Shenton ME, Dickey CC, Frumin M and McCarley RW: A review of MRI findings in schizophrenia. Schizophr Res 49: 1-52, 2001

12. Kwon JS, Shenton ME, Hirayasu Y, Salisbury DF, Fischer IA, Dickey CC, Yurgelun-Todd D, Tohen M, Kikinis R, Jolesz FA and McCarley RW: MRI study of cavum septi pellucidi in schizophrenia, affective disorder, and schizotypal personality disorder. Am J Psychiatry 155: 509-515, 1998.

13. Akhtar W, Naqvi HA, Hussain S, Ali A and Ahmad N: Magnetic Resonance Imaging Findings in Patients with Schizophrenia. J Coll Physicians Surg Pak 20: 167-170, 2010.

14. Najjar S and Pearlman DM: Neuroinflammation and white matter pathology in schizophrenia: Systematic review. Schizophr Res 161: 102-112, 2015

15. Chew LJ, Fusar-Poli $\mathrm{P}$ and Schmitz T: Oligodendroglial alterations and the role of microglia in white matter injury: Relevance to schizophrenia. Dev Neurosci 35: 102-129, 2013

16. Ohnuma T, Kimura M, Takahashi T, Iwamoto N and Arai H: A magnetic resonance imaging study in first-episode disorganized-type patients with schizophrenia. Psychiatry Clin Neurosci 51: 9-15, 1997

17. DeLisi LE, Sakuma M, Tew W, Kushner M. Hoff AL and Grimson R: Schizophrenia as a chronic active brain process: A study of progressive brain structural change subsequent to the onset of schizophrenia. Psychiatry Res 74: 129-140, 1997.

18. DeLisi LE, Stritzke P, Riordan H, Holan V, Boccio A, Kushner M, McClelland J, Van Eyl O and Anand A: The timing of brain morphological changes in schizophrenia and their relationship to clinical outcome. Biol Psychiatry 31: 241-254, 1992.

19. DeLisi LE, Tew W, Xie S, Hoff AL, Sakuma M, Kushner M, Lee G, Shedlack K, Smith AM and Grimson R: A prospective follow-up study of brain morphology and cognition in first-episode schizophrenic patients: Preliminary findings. Biol Psychiatry 38: 349-360, 1995.
20. Coulon N, Godin O, Bulzacka E, Dubertret C, Mallet J, Fond G, Brunel L, Andrianarisoa M, Anderson G, Chereau I, et al: Early and very early-onset schizophrenia compared with adult-onset schizophrenia: French FACE-SZ database. Brain Behav 10: e01495-e01495, 2020.

21. Wright IC, Rabe-Hesketh S, Woodruff PW, David AS, Murray RM and Bullmore ET: Meta-analysis of regional brain volumes in schizophrenia. Am J Psychiatry 157: 16-25, 2000.

22. Matsumoto H, Simmons A, Williams S, Pipe R, Murray R and Frangou S: Structural magnetic imaging of the hippocampus in early onset schizophrenia. Biol Psychiatry 49: 824-831, 2001.

23. Margari F, Presicci A, Petruzzelli MG, Ventura P, Di Cuonzo F, Palma $\mathrm{M}$ and Margari L: Very early onset and greater vulnerability in schizophrenia: A clinical and neuroimaging study. Neuropsychiatr Dis Treat 4: 825-830, 2008

24. Degreef G, Bogerts B, Falkai P, Greve B, Lantos G, Ashtari M and Lieberman J: Increased prevalence of the cavum septum pellucidum in magnetic resonance scans and post-mortem brains of schizophrenic patients. Psychiatry Res 45: 1-13, 1992.

25. Tordesillas-Gutierrez D, Koutsouleris N, Roiz-Santiañez R, Meisenzahl E, Ayesa-Arriola R, Marco de Lucas E, Soriano Mas C, Suarez Pinilla P and Crespo-Facorro B: Grey matter volume differences in non-affective psychosis and the effects of age of onset on grey matter volumes: A voxelwise study. Schizophr Res 164: 74-82, 2015

26. Narr KL, Bilder RM, Toga AW, Woods RP, Rex DE, Szeszko PR, Robinson D, Sevy S, Bruce HG, Wang YP, DeLuca H and Thompson PM: Mapping cortical thickness and gray matter concentration in first episode schizophrenia. Cereb Cortex 15: 708-719, 2005.

27. Gogtay N: Cortical brain development in schizophrenia: Insights from neuroimaging studies in childhood-onset schizophrenia. Schizophr Bull 34: 30-36, 2008.

28. Mathalon DH, Sullivan EV, Lim KO and Pfefferbaum A: Progressive brain volume changes and the clinical course of schizophrenia in men: A longitudinal magnetic resonance imaging study. Arch Gen Psychiatry 58: 148-157, 2001.

29. Gur RE, Cowell P, Turetsky BI, Gallacher F, Cannon T, Bilker W and Gur RC: A follow-up magnetic resonance imaging study of schizophrenia. Relationship of neuroanatomical changes to clinical and neurobehavioral measures. Arch Gen Psychiatry 55: 145-152, 1998

30. Lieberman J, Chakos M, Wu H, Alvir J, Hoffman E, Robinson D and Bilder R: Longitudinal study of brain morphology in first episode schizophrenia. Biol Psychiatry 49: 487-499, 2001.

31. Ho BC, Andreasen NC, Nopoulos P, Arndt S, Magnotta V and Flaum M: Progressive structural brain abnormalities and their relationship to clinical outcome: A longitudinal magnetic resonance imaging study early in schizophrenia. Arch Gen Psychiatry 60: 585-594, 2003.

32. Rapoport JL, Castellanos FX, Gogate N, Janson K, Kohler S and Nelson P: Imaging normal and abnormal brain development: New perspectives for child psychiatry. Aust N Z J Psychiatry 35: 272-281, 2001.

33. Nopoulos P, Torres I, Flaum M, Andreasen NC, Ehrhardt JC and Yuh WT: Brain morphology in first-episode schizophrenia. Am J Psychiatry 152: 1721-1723, 1995.

34. van Haren NEM, Cahn W, Hulshoff Pol HE and Kahn RS: Schizophrenia as a progressive brain disease. Eur Psychiatry 23: 245-254, 2008

35. Kasai K, Shenton ME, Salisbury DF, Hirayasu Y, Lee CU, Ciszewski AA, Yurgelun-Todd D, Kikinis R, Jolesz FA and McCarley RW: Progressive decrease of left superior temporal gyrus gray matter volume in patients with first-episode schizophrenia. Am J Psychiatry 160: 156-164, 2003.

36. Kay SR, Fiszbein A and Opler LA: The Positive and Negative Syndrome Scale (PANSS) for schizophrenia. Schizophr Bull 13: 261-276, 1987.

37. Addington $\mathrm{D}$, Addington $\mathrm{J}$ and Schissel $\mathrm{B}$ : A depression rating scale for schizophrenics. Schizophr Res 3: 247-251, 1990.

38. Sheehan KH and Sheehan DV: Assessing treatment effects in clinical trials with the discan metric of the sheehan disability scale. Int Clin Psychopharmacol 23: 70-83, 2008.

39. Mioshi E, Dawson K, Mitchell J, Arnold R and Hodges JR: The Addenbrooke's Cognitive Examination Revised (ACE-R): A brief cognitive test battery for dementia screening. Int J Geriatr Psychiatry 21: 1078-1085, 2006.

40. American Psychiatric Association: Diagnostic and statistical manual of mental disorders. 4th edition. American Psychiatric Publishing, Inc., Washington, DC, 1994. 
41. World Health Organization: The ICD-10 classification of mental and behavioural disorders: Diagnostic criteria for research. WHO Press, Geneva, 1993.

42. Taber KH, Shaw JB, Loveland KA, Pearson DA, Lane DM and Hayman LA: Accentuated Virchow-Robin spaces in the centrum semiovale in children with autistic disorder. J Comput Assist Tomogr 28: 263-268, 2004.

43. PatankarTF, Mitra D, Varma A, Snowden J, Neary D and Jackson A: Dilatation of the virchow-robin space is a sensitive indicator of cerebral microvascular disease: Study in elderly patients with dementia. AJNR Am J Neuroradiol 26: 1512-1520, 2005.

44. Wuerfel J, Haertle M, Waiczies H, Tysiak E, Bechmann I, Wernecke KD, Zipp F and Paul F: Perivascular spaces-MRI marker of inflammatory activity in the brain? Brain 131: 2332-2340, 2008.

45. Davis KL, Stewart DG, Friedman JI, Buchsbaum M, Harvey PD, Hof PR, Buxbaum J, and Haroutunian V: White matter changes in schizophrenia: evidence for myelin-related dysfunction. Arch Gen Psychiatry 60: 443-456, 2003.

46. Smith AB and Ross CM: Nasal sinusitis and mental disorder. A survey of 818 cases. Edinb Med J 45: 343-356, 1938.

47. Ciobanu AM, Rosca T, Vladescu CT, Tihoan C, Popa MC, Boer MC and Cergan R: Frontal epidural empyema (Pott's puffy tumor) associated with Mycoplasma and depression. Rom J Morphol Embryol 55: 1203-1207, 2014.

48. Moncrieff $\mathbf{J}$ and Leo $\mathrm{J}$ : A systematic review of the effects of antipsychotic drugs on brain volume. Psychol Med 40: 1409-1422, 2010.

49. Lieberman JA, Tollefson GD, Charles C, Zipursky R, Sharma T, Kahn RS, Keefe RS, Green AI, Gur RE, McEvoy J, et al: Antipsychotic drug effects on brain morphology in first-episode psychosis. Arch Gen Psychiatry 62: 361-370, 2005.
50. Cahn W, Hulshoff Pol HE, Lems EB, van Haren NE, Schnack HG, van der Linden JA, Schothorst PF, van Engeland H and Kahn RS: Brain volume changes in first-episode schizophrenia: A 1-year follow-up study. Arch Gen Psychiatry 59: 1002-1010, 2002.

51. Jayakumar PN, Venkatasubramanian G, Gangadhar BN, Janakiramaiah $\mathrm{N}$ and Keshavan MS: Optimized voxel-based morphometry of gray matter volume in first-episode, antipsychotic-naive schizophrenia. Prog Neuropsychopharmacol Biol Psychiatry 29: 587-591, 2005.

52. Davatzikos C, Shen D, Gur RC, Wu X, Liu D, Fan Y, Hughett P, Turetsky BI and Gur RE: Whole-brain morphometric study of schizophrenia revealing a spatially complex set of focal abnormalities. Arch Gen Psychiatry 62: 1218-1227, 2005.

53. Ciobanu AM, Lisievici MG, Coman TC, Ciubotaru GV, Drăghia A, Drăghia F and Ciucu AA: Giant wing sphenoid meningioma with principal manifestation depression. Rom J Morphol Embryol 50: 713-717, 2009.

54. Ciobanu AM, Popa C, Marcu M and Ciobanu CF: Psychotic depression due to giant condyloma Buschke-Löwenstein tumors. Rom J Morphol Embryol 55: 189-195, 2014

(i) $\Theta$ This work is licensed under a Creative Common Attribution-NonCommercial-NoDerivatives 4.0 International (CC BY-NC-ND 4.0) License. 